\title{
Deep-Sea Oil Plume Enriches Psychrophilic Oil-Degrading Bacteria
}

\author{
Terry C. Hazen, ${ }^{1 *}$ Eric A. Dubinsky, ${ }^{1}$ Todd Z. DeSantis, ${ }^{1}$ Gary L. Andersen, ${ }^{1}$ Yvette M. Piceno, ${ }^{1}$ \\ Navjeet Singh, ${ }^{1}$ Janet K. Jansson, ${ }^{1}$ Alexander Probst, ${ }^{1}$ Sharon E. Borglin, ${ }^{1}$ Julian L. Fortney, ${ }^{1}$ \\ William T. Stringfellow, ${ }^{1,2}$ Markus Bill, ${ }^{1}$ Mark E. Conrad, ${ }^{1}$ Lauren M. Tom, ${ }^{1}$ Krystle L. \\ Chavarria, ${ }^{1}$ Thana R. Alusi, ${ }^{1}$ Regina Lamendella, ${ }^{1}$ Dominique C. Joyner, ${ }^{1}$ Chelsea Spier, ${ }^{2}$ Jacob \\ Baelum, ${ }^{1}$ Manfred Auer, ${ }^{1}$ Marcin L. Zemla, ${ }^{1}$ Romy Chakraborty, ${ }^{1}$ Eric L. Sonnenthal, ${ }^{1}$ Patrik \\ D haeseleer, ${ }^{4}$ Hoi-Ying N. Holman, ${ }^{1}$ Shariff Osman, ${ }^{1}$ Zhenmei Lu, ${ }^{3}$ Joy D. Van Nostrand, ${ }^{3}$ Ye \\ Deng, ${ }^{3}$ Jizhong Zhou, ${ }^{1,3}$ Olivia U. Mason ${ }^{1}$

\footnotetext{
${ }^{1}$ One Cyclotron Road, Lawrence Berkeley National Laboratory, Berkeley, CA 94720, USA. 95211, USA.

${ }^{3}$ University of Oklahoma, 101 David L. Boren Boulevard, Norman, OK 73072, USA.

${ }^{4}$ Biosciences and Biotechnology Division, Lawrence Livermore National Laboratory, Livermore, CA 94550, USA.
} \\ ${ }^{2}$ University of the Pacific, Ecological Engineering Research Program, 3601 Pacific Avenue, Stockton, CA
}

\begin{abstract}
The biological effects and expected fate of the vast amount of oil in the Gulf of Mexico from the Deepwater Horizon blowout are unknown owing to the depth and magnitude of this event. Here, we report that the dispersed hydrocarbon plume stimulated deep-sea indigenous $\gamma$-Proteobacteria that are closely related to known petroleum degraders. Hydrocarbon-degrading genes coincided with the concentration of various oil contaminants. Changes in hydrocarbon composition with distance from the source and incubation experiments with environmental isolates demonstrated faster-than-expected hydrocarbon biodegradation rates at $5^{\circ} \mathrm{C}$. Based on these results, the potential exists for intrinsic bioremediation of the oil plume in the deep-water column without substantial oxygen drawdown.
\end{abstract}

Assessing the environmental and public health impacts of the Deepwater Horizon blowout is difficult owing to the extreme depth of the blowout and the large volumes of oil released. Moreover, the effectiveness of the primary initial mitigation strategy (e.g., injecting the oil dispersant Corexit 9500 directly at the wellhead in a water depth of $1544 \mathrm{~m}$ ) is difficult to assess despite initial analysis of its potential toxicity (1). An optional strategy for remediation of the deep underwater plume is to use the intrinsic bioremediation potential of deep-sea microorganisms to degrade the oil. This strategy depends on a number of environmental factors, including a favorable response of indigenous microorganisms to an increased concentration of hydrocarbons and/or dispersant.

To determine the impact of the deep hydrocarbon plume on the marine microbes residing in the plume and the rates of hydrocarbon biodegradation, we collected deep-water samples from two ships between 25 May 2010 and 2 June 2010. In total, we analyzed the physical, chemical, and microbiological properties of 17 deepwater samples from across the Gulf of Mexico (2).

We detected a deep-sea oil plume from 1099 to $1219 \mathrm{~m}$ at distances of up to $10 \mathrm{~km}$ from the wellhead. Owing to its composition, the plume was likely dispersed MC252 oil, a conclusion also reached by Camilli et al. (3). At most locations where the plume was detected, there was a slight decrease in oxygen concentration indicative of microbial respiration and oxygen consumption, as would be expected if the hydrocarbons were being catabolized (Fig. 1). Oxygen saturation within 
the plume averaged 59\%, while outside the plume it was $67 \%$. Extractable hydrocarbons (e.g., octadecane) ranged from nondetectable in the nonplume samples to $9.21 \mu \mathrm{g} /$ liter in plume samples. Volatile aromatic hydrocarbons were significantly higher in the plume interval (mean $139 \mu \mathrm{g} /$ liter) than in the nonplume samples from similar depths. The average temperature within the plume interval was $4.7^{\circ} \mathrm{C}$ and the pressure was $1136 \mathrm{~dB}$. Soluble orthophosphate, and total ammonia-N, were detected at similar concentrations within and outside the plume interval (table S1).

The dispersed oil plume affected both microbial cell densities and composition (Fig. 1). Cell densities in the plume $\left(5.51 \pm 0.33 \times 10^{4}\right.$ cells $\left./ \mathrm{ml}\right)$ were higher than outside the plume $(2.73 \pm$ $0.05 \times 10^{4}$ cells $\left./ \mathrm{ml}\right)$. Phospholipid fatty acid analysis also confirmed an increase in microbial biomass in the plume $(0.57 \mathrm{pmol}$ lipids $/ \mathrm{ml})$ versus outside the plume $(0.23 \mathrm{pmol}$ lipids $/ \mathrm{ml})$. In addition to the observed increase in cell densities, PhyloChip 16S ribosomal RNA (rRNA) microarray analysis suggests that the plume significantly altered the microbial community composition and structure. Ordination of bacterial and archaeal 16S rRNA gene composition revealed two distinct clusters of samples: one composed entirely of plume samples with detected oil and the other of nonplume samples (Fig. 2). No physical or chemical factors other than hydrocarbons and nitrates were significantly different between these groups, indicating that microorganisms were responding directly to the presence of dispersed oil.

In plume samples, PhyloChip analysis revealed that 951 distinct bacterial taxa in 62 phyla were present, but only 16 distinct taxa that were all classified as $\gamma$-Proteobacteria were significantly enriched in the plume relative to nonplume samples. Nearly all of these enriched taxa have representatives that degrade hydrocarbons or are stimulated by the presence of oil in cold environments. Plume-enriched bacteria include many psychrophilic and psychrotolerant species that have been observed in low-temperature marine environments (table S2) (4-6). Although cell densities are higher in the plume, taxonomic richness was lower and the diversity of enriched bacteria was restricted to a few $\gamma$-Proteobacteria.

Cloning and sequencing revealed that deep-sea plume samples from station BM58 ( $\sim 10.08$ $\mathrm{km}$ from the MC252 wellhead) and station OV011 ( 1.5 km from the wellhead) were dominated by the order Oceanospirillales in the $\gamma$-Proteobacteria. More than $90 \%$ of all sequences in both plume samples ( $10 \mathrm{~km}$ between sampling stations) belonged to a single operational taxonomic unit (OTU) that is most closely related to Oceanospirillales (Fig. 3). In a control sample (site OV003) collected $39.1 \mathrm{~km}$ southwest of the wellhead, this same OTU represented only $5 \%$ of all sequences analyzed (Fig. 3). In addition, this taxon was detected in all 10 oil plume samples analyzed by the PhyloChip and was significantly enriched relative to background deep seawater with no oil. The cultured representatives most closely related to the OTU in plume samples were Spongiispira norvegica (95\% similar) and Oceaniserpentilla haliotidis (94\% similar). The observed sequences in the plume samples form a clade with two distinct Oceanospirillales groups. One of these groups is largely composed of known psychrophilic hydrocarbon degraders and microorganisms from hydrocarbon-dominated environments $(5,7,8)$, including Oleispira antarctica, Thalassolituus oleivorans, and Oleiphilus messinensis.

The three dominant phospholipid fatty acids detected in the plume samples were C16:0, C16:1w7c, and C18:1w9c, which have been reported as the dominant lipids in the Oleispirea antarctica, in some strains of the Oceaniserpentilla haliotis (4), and in a consortium of marine hydrocarbon-degrading bacteria (9). 18:1w9t/c ratios that have been reported to increase in oilcontaminated environments $(10,11)$ were slightly elevated in plume samples (average 0.21 ) compared to nonplume samples (average 0.14 ) but were not strongly correlated with oil concentrations. Multivariate analysis of phospholipid fatty acid (PLFA) profiles from each sample revealed distinct clustering of plume and nonplume samples similar to community analysis of microarray data (Fig. 2).

Microscopic examination of cells collected within the plume also revealed that the dominant cell type exhibits a distinctive morphology typical of the Oceanospirillales (Fig. 4). Total 
bacterial densities were also significantly correlated with MC252 alkane concentration in the plume. Synchrotron radiation-based Fourier transform infrared (SR-FTIR) spectromicroscopy revealed absorptions at $\sim 1730, \sim 1610$, and $\sim 1150 \mathrm{~cm}^{-1}$ that are associated with biomolecule-rich regions of a cellular floc (Fig. 3). These absorption features are well described for the carbonyl $(\mathrm{C}=\mathrm{O})$, nitrogen oxides, and sulfur oxides vibration modes (12) and are characteristic of oil degradation products (13). These SR-FTIR spectra are not consistent with those typically found in marine macroaggregates (14), nor are they consistent with nonplume samples at the same depth.

To understand the distribution of oil-degrading genes within the plume, we analyzed five samples (BM053, BM054, BM057, BM058, BM064) from the MC252 dispersed oil plume as well as five uncontaminated, control samples (OV003, OV004, OV009, OV013 and OV014) collected from plume depth with GeoChip functional array $(15,16)$. Altogether, 4000 to 5000 functional genes were detected per sample, among which 1652 genes are involved in hydrocarbon degradation. Detrended correspondence analysis showed that microbial community functional composition and structure were considerably different between oil-plume and nonplume control samples, which is consistent with PhyloChip analysis. Many of the genes involved in hydrocarbon degradation were significantly $(\mathrm{P}<0.05$ or 0.01$)$ increased in oil plume samples. Statistical analysis by Mantel test showed that the overall microbial functional composition and structure were significantly correlated with many key oil contaminants, including isopropylbenzene, $n$-propylbenzene, tert-butylbenzene, 1,2,4 trimethylbenzene, $p$ isopropyltoluene, $n$-butylbenzene, and naphthalene. Analysis based on individual genes showed that the changes of many hydrocarbon degradation genes are significantly correlated with the concentrations of oil contaminants. For instance, the phdCI gene encoding carboxylate isomerase for naphthalene degradation correlates with several hydrocarbons. These results indicated that a variety of hydrocarbon-degrading populations exist in the deep-sea plume and that the microbial communities appear to be undergoing rapid dynamic adaptation in response to oil contamination. These results also imply that there exists a potential for intrinsic bioremediation of oil contaminants in the deep sea and that oil-degrading communities could play an important role in controlling the ultimate fates of hydrocarbons in the Gulf.

The bioremediation potential largely depends on the rates of biodegradation in the plume. We calculated maximum biodegradation rates using two data sets from the field and two from laboratory microcosms representing concentrations of $\mathrm{C} 13$ to $\mathrm{C} 26 n$-alkanes. The degradation rate coefficients and half-life values, calculated from the alkane data from these four sources with the first-order rate equation $(10,17)$, are similar to those reported for comparable temperature and field conditions $(10,17-19)$. Despite the varying field and microcosm conditions, the oil halflives are 1.2 to 6.1 days. The field half-lives should in part reflect the effect of mixing and dilution, but the similarity of the rate of disappearance of alkanes in the plume to the rates observed in the laboratory suggest it is possible that the actual degradation of alkanes lies within this range. The possibility that biodegradation largely controls the disappearance of alkanes is also supported by the preferential degradation of short-chain alkanes, as represented in the increase in the ratio of $\mathrm{C} 26 / \mathrm{C} 15$ alkanes over $10 \mathrm{~km}$, from less than 1 to more than 3 . For each data set, decay constants were similar for all alkanes measured in all samples, with the exception of the plume samples from the nonlipid fraction collected on $0.2-\mu \mathrm{m}$ filters. Because these results represent extraction from free-phase oil or oil absorbed to the membrane filter, it is likely that the higher rates seen for the shorter-chain alkanes are due to additional losses in collected sample resulting from dissolution into seawater; however, there is a correlation of longer-chain alkane concentration with cell densities in the plume. The oil biodegradation rates reported here at $5^{\circ} \mathrm{C}$ are explained partly by the relatively light nature of this crude (which contains a large volatile component that is more readily degraded), the dispersed nature of the deep plume (small oil particle size), the low overall concentrations of oil in the deep plume, and the frequent episodic oil leaks from natural seeps in this area that the deep-sea microbial community may have adapted to over long periods of time. 


\section{References and Notes}

1. R. S. Judson et al., Environ. Sci. Technol. 44, 5979 (2010).

2. Materials and methods are available on Science Online.

3. R. Camilli et al., Science 330, 201 (2010); published online 19 August 2010 (10.1126/science.1195223).

4. A. Schlösser, A. Lipski, J. Schmalfuss, F. Kugler,

G. Beckmann, Int. J. Syst. Evol. Microbiol. 58, 2122 (2008).

5. M. M. Yakimov et al., Int. J. Syst. Evol. Microbiol. 53, 779 (2003).

6. M. M. Yakimov, K. N. Timmis, P. N. Golyshin, Curr. Opin.

Biotechnol. 18, 257 (2007).

7. G. Gentile et al., Environ. Microbiol. 8, 2150 (2006).

8. M. M. Yakimov et al., FEMS Microbiol. Ecol. 49, 419 (2004).

9. E. Aries, P. Doumenq, J. Artaud, M. Acquaviva,

J. C. Bertrand, Org. Geochem. 32, 891 (2001).

10. S. J. MacNaughton et al., Appl. Environ. Microbiol. 65, 3566 (1999).

11. S. M. Pfiffner et al., Geomicrobiol. J. 23, 431 (2006).

12. G. Socrates, Infrared and Raman Characteristics Group Frequencies-Tables and Charts (Wiley, Chichester, UK,ed. 3, 2001).

13. N. Robinson, Wearcheck Tech. Bull. (2000); www.machinerylubrication.com/Read/1109/oildegradationspectroscopy.

14. N. Kovac, O. Bajt, J. Faganeli, B. Sket, B. Orel, Mar. Chem. 78, 205 (2002).

15. Z. He et al., ISME J. 4, 1167 (2010).

16. Z. L. He et al., ISME J. 1, 67 (2007).

17. A. D. Venosa, E. L. Holder, Mar. Pollut. Bull. 54, 545 (2007).

18. R. Atlas, J. Bragg, Microb. Biotechnol. 2, 213 (2009).

19. O. G. Brakstad, K. Bonaunet, Biodegradation 17, 71 (2006).

20. D. Naumann, in Encyclopedia of Analytical Chemistry, R. Meyers, Ed. (Wiley, Chichester, UK, 2000), pp. 102-131.

21. This work was supported by a subcontract from the University of California at Berkeley, Energy Biosciences Institute, to Lawrence Berkeley National Laboratory under U.S.

Department of Energy contract DE-AC02-05CH11231 and by the University of Oklahoma Research Foundation. The Energy Biosciences Institute is funded by British Petroleum. The SR-FTIR work was conducted at the infrared beamline at the Advanced Light Source, which is supported by the Director, Office of Science, Office of Basic Energy Sciences, of the U.S. Department of Energy. We thank T. Pollard, K. Keller, M. Carrera, P. Willems, P. Carragher, P. Collinson, S. Lisiecki, P. Vaishampayan, R. Graham, J. Wong, N. Duncan, D. Long, and N. Tam for logistical and technical support. We also thank the captain, crew, and science teams aboard the R/V Ocean Veritas and the R/V Brooks McCall. The National Center for Biotechnology Information accession numbers of the 16S rRNA genes retrieved from clone library analyses are HM587888, HM587889, and HM587890. Sequences for 16S rRNA are also available at greengenes.lbl.gov. 

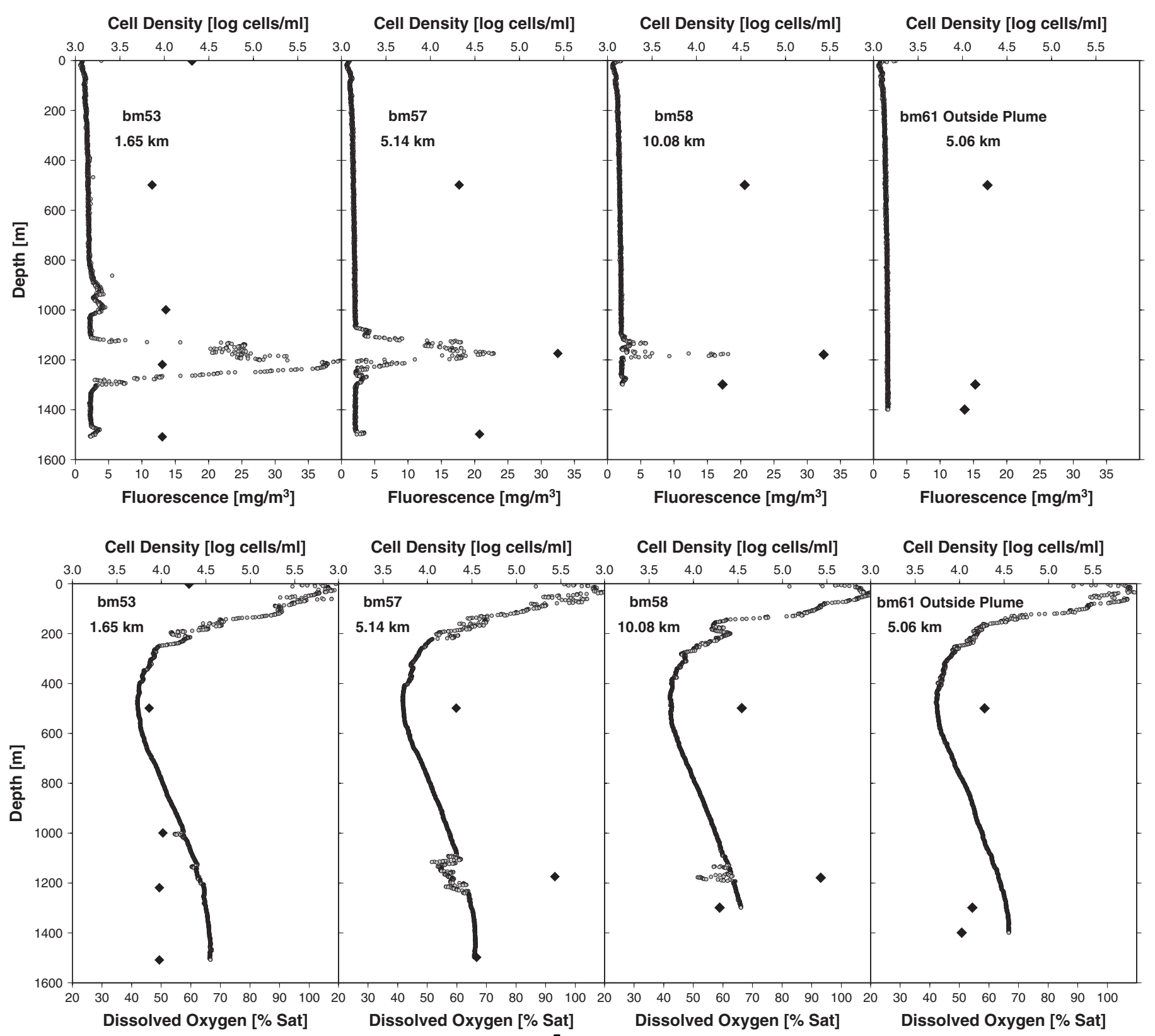

Fig. 1. Characteristic depth profiles of cell density, fluorescence, and dissolved oxygen for distances from the source (BM53, BM57, and BM58) and one nonplume site (BM61). Diamonds indicate cell density. 
Fig. 2. Microbial community analysis of deepwater plume and nonplume samples. Differences in composition of (A) $16 \mathrm{~S}$ rRNA gene sequences measured by PhyloChip and (B) phospholipid fatty acids were analyzed with nonmetric multidimensional scaling ordination of Bray-Curtis distances (stress $=3.98$ and 4.55, respectively). Plume and nonplume communities were significantly different as determined by permutational analysis of variance $(P=0.005$ for both) and delineated with lines for clarity.
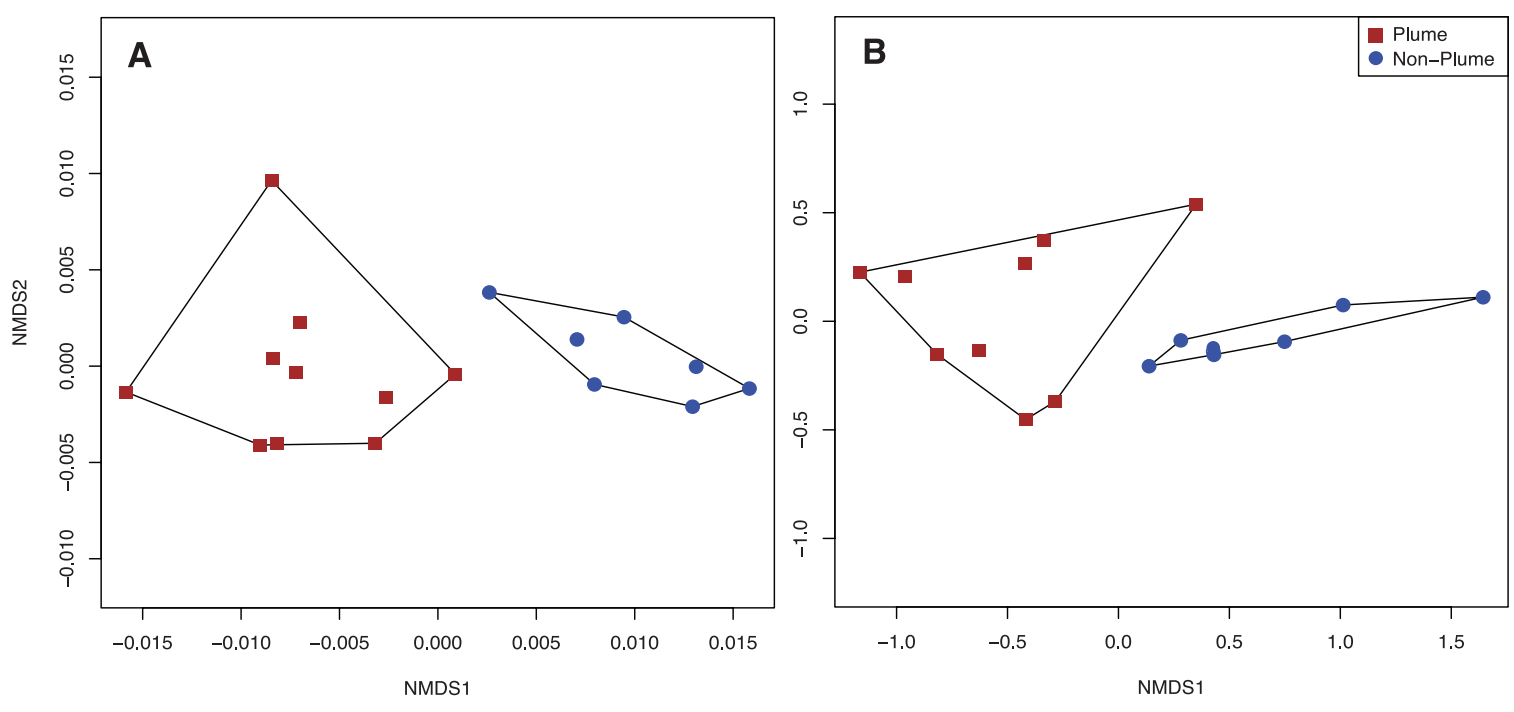

Fig. 3. SR-FTIR images $(\sim 60 \mu \mathrm{m}$ by $60 \mu \mathrm{m}$ ) showing the distribution of microorganisms, oil, and oil degradation products in a "floc." Distribution heat map of the protein amide II vibration modes at $\sim 1542 \mathrm{~cm}^{-1}$ and the carbohydrates vibration modes at $\sim 1000 \mathrm{~cm}^{-1}$ (20). Distribution heat map of alkane $\mathrm{C}-\mathrm{H}$ vibration modes in oil from MC252. Distribution heat map of carbonyl $(C=0)$ vibration modes at $\sim 1730 \mathrm{~cm}^{-1}$ in oil oxidation products, of nitrogen oxides vibration modes at $\sim 1610 \mathrm{~cm}^{-1}$ in nitration products, and of sulfur oxides vibration modes at $\sim 1150 \mathrm{~cm}^{-1}$ in sulfation products. Scale bars: $10 \mu \mathrm{m}$. Reflectance is given in percentage units.

\section{SR-FTIR analysis of Sample \# OV01105}

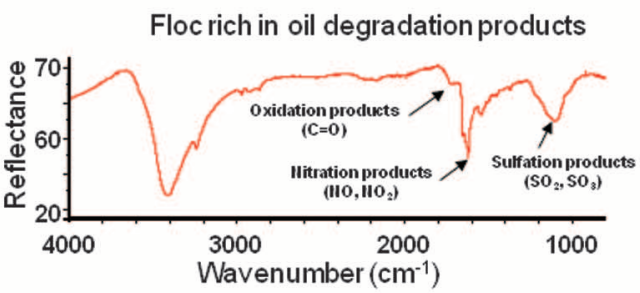

Microbe-rich floc with oil degradation products
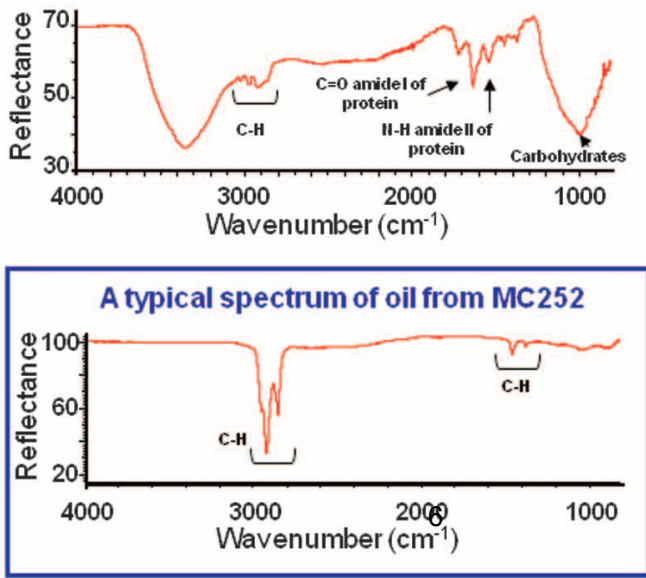

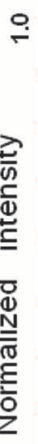

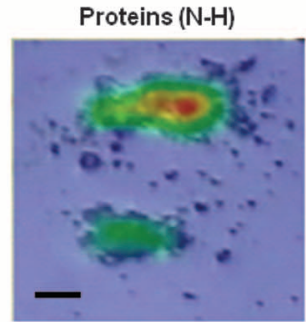

Alkane (C-H)

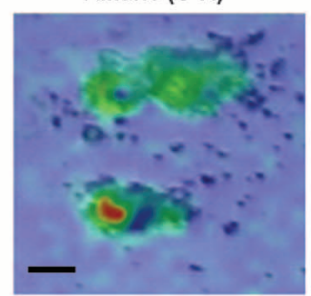

$\circ$
Nitration products

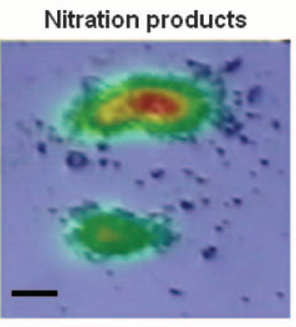

Scale bars $=10$ micrometers

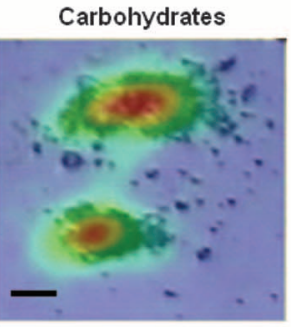

Oxidation products

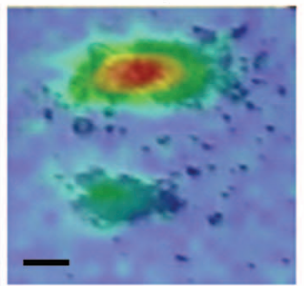

Sulfation products

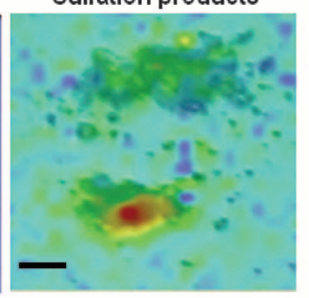



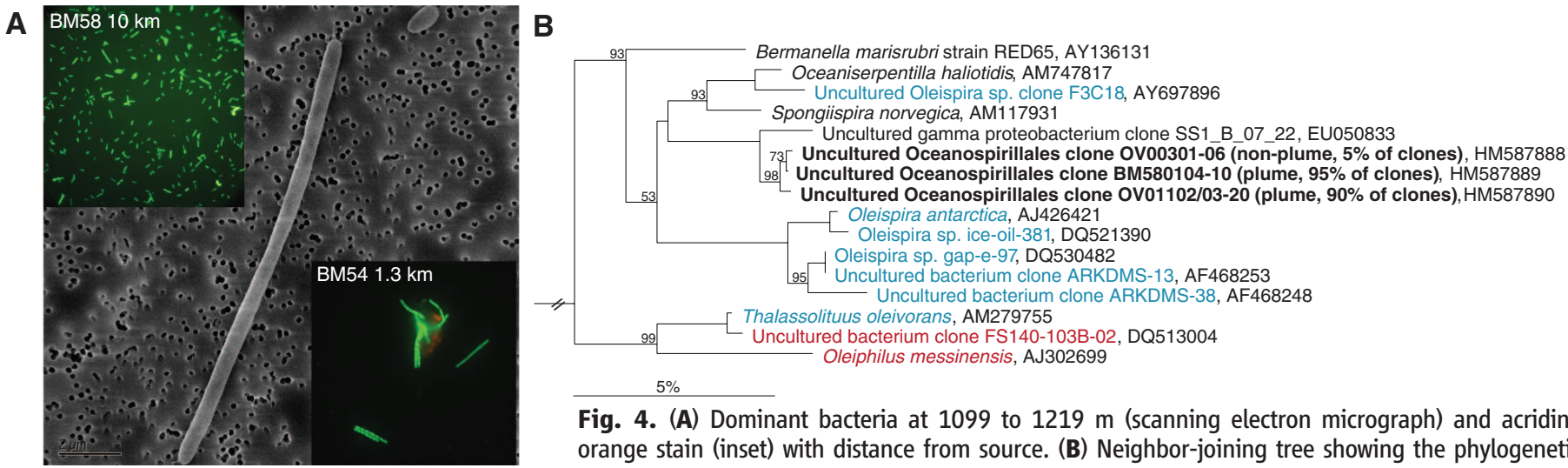

Fig. 4. (A) Dominant bacteria at 1099 to $1219 \mathrm{~m}$ (scanning electron micrograph) and acridine orange stain (inset) with distance from source. (B) Neighbor-joining tree showing the phylogenetic relationships of the dominant bacterium in deep-sea plume samples. Relative abundance of the dominant bacterium was 90 to $95 \%$ of plume samples and $5 \%$ of the nonplume sample (shown in parentheses). Psychrophilic, hydrocarbon-degrading bacteria, as well as uncultured organisms from low-temperature, hydrocarbon-dominated environments, are shown in blue. Organisms shown in red are either known hydrocarbon degraders or are from hydrocarbon-dominated ecosystems but are not from low-temperature environments. Bootstrap values based on 1000 replicates of $\geq 50 \%$ are shown at branch points. Aquifex pyrophilus (GenBank accession M83548) was used as the outgroup. 


\section{DISCLAIMER}

This document was prepared as an account of work sponsored by the United States Government. While this document is believed to contain correct information, neither the United States Government nor any agency thereof, nor The Regents of the University of California, nor any of their employees, makes any warranty, express or implied, or assumes any legal responsibility for the accuracy, completeness, or usefulness of any information, apparatus, product, or process disclosed, or represents that its use would not infringe privately owned rights. Reference herein to any specific commercial product, process, or service by its trade name, trademark, manufacturer, or otherwise, does not necessarily constitute or imply its endorsement, recommendation, or favoring by the United States Government or any agency thereof, or The Regents of the University of California. The views and opinions of authors expressed herein do not necessarily state or reflect those of the United States Government or any agency thereof or The Regents of the University of California.

Ernest Orlando Lawrence Berkeley National Laboratory is an equal opportunity employer. 